\title{
The application of power electronic transformer in distribution power system
}

\author{
J.Y. $\operatorname{Bian}^{1} \&$ G.Y.Qiu ${ }^{1}$ \\ ${ }^{1}$ School of Electrical Engineering, Guizhou University, Guiyang, Guizhou, China
}

KEYWORD: Power electronic transformer; High-frequency transformer; Power quality; The power supply reliability.

ABSTRACT: Transformer for electric energy conversion of the most basic components in power system, is also one of the most widely used electrical equipment, its operation stability, the quality of power supply and technical and economic indicators will be directly related to the working condition of electrical equipment. Conventional power transformer, although after the development of more than a century, the performance and process have been very mature, as for electric power system, its increase of the power supply reliability and power quality do not have much effect on the improvement. In this paper, a new intelligent multi-functional transformer--power electronic transformer, it not only has the function of traditional power transformer voltage level of power transmission and transformation, electrical isolation and power delivery, but also can improve power supply reliability, improve power quality, the advantages of small size are friendly to environment. First, this paper introduces the working principle of the power electronic transformer, the main topology structure; Then, through the simulation analysis of the advantages compared with traditional transformer power electronic transformer; Finally, the developing trend of power electronic transformer is analyzed and summarized in this paper.

\section{THE INTRODUCTION}

Along with the rapid development of social economy, power grid scale expands increasingly, besides all kinds of distributed power supply, power electronic devices become more widely used, the smart grid develops rapidly, nonlinear and sensitive load increase endlessly, the requirement of the users' equipment for power supply reliability and power quality becomes high increasingly.

Use On the other hand, the rapid development of economy cannot be without the energy support, people's demands for energy increase greatly. Due to oil, natural gas, coal and other non-renewable fossil energy reserves are limited, in the near future they will eventually run out. Therefore, distributed generation systems of wind power, solar power and other clean renewable energy also gradually improve in the proportion of power system. But how the new energy can be efficient and reliably fit in the whole power system running is a big problem that we are facing.

Since traditional power transformer was invented in the early 19 th century, it has gradually become the important equipment of transmission system and distribution system. A huge number of its application is mainly used in a voltage level of power transmission and transformation, electrical isolation. Traditional power transformer reliably operates and has high efficiency, but it also has the following shortcomings ${ }^{[1]}$ :

1 , their size and quality are big relatively;

2, transformer oil will cause environmental pollution;

3 , once the core saturates, the system will generate a large number of harmonic component, may cause serious phenomena of excitation inrush current;

4, either of party fails, breakdown voltage, electric current will be reached to the other side through the electromagnetic coupling, load fluctuation will affect the grid side;

5 , need relaying protection device;

6 , cannot effectively isolate the harmonic current and three-phase unbalance.

Due to the above content has noticed the shortcomings of traditional power transformer, we have to meet the function on the basis of the traditional power transformer, to further expand its function, improve its operation features in order to better play its role in the power supply system, thus further improve power supply reliability and power quality. As Power Electronic components produc- 
tion technology and its controlling way breakthrough improve unceasingly, a kind of Power Electronic components and its control technology and the combination of high frequency Transformer make transformation of the different characteristics of electric Power electricity transformation of new intelligent come true- Power Electronic Transformer (Power Electronic Transformer, or PET) by the attention of more and more high ${ }^{[2]}$.

\section{THE PRINCIPLE OF PET}

Power Electronic Transformer (PET), also known as Solid State Transformer (SST), or Electronic Transformer(ET), is a kind of a new type of Transformer energy transfer through Power Electronic technology to achieve the Power system voltage transformation. Power electronic transformer is mainly composed of power electronic converter and high frequency transformer. The role of high frequency transformer is to provide electrical isolation and voltage grade transformation; The role of the power electronic converter is to realize the waveform control, such as: frequency control and phase control, harmonic control, etc. Power electronic transformer substation can be used for ac power transformation, both also can be used in dc power transformation or ac/dc hybrid power transformation. Therefore, in the form of transformation of electrical energy, power electronic transformer can be divided into three types: AC power electronic transformer (AC - PET), DC power electronic transformer (DC - PET) and AC/DC Hybrid power electronic transformer (Hybrid PET) ${ }^{[3]}$.

Figure 1 shows the principle of structure of power electronic transformer. Its working principle is: when a side received power, the power electronic converter 1 will input electric transform into high frequency alternating current (ac); High frequency alternating current applied to the high frequency converter is connected with the side of a winding, winding of alternating current flow, according to the law of electromagnetic induction, high frequency transformer of secondary winding produce inductive electromotive force; Induction electromotive force is applied to power electronic converters are connected to the secondary winding 2, after its transformation into the required form of electricity output, supply power to the load.

\section{THE TOPOLOGY OF THE PET}

Using the different structure of the power electronic converter, the researchers have proposed a variety of PET topology for alternating current (ac). In these implementation schemes, from whether

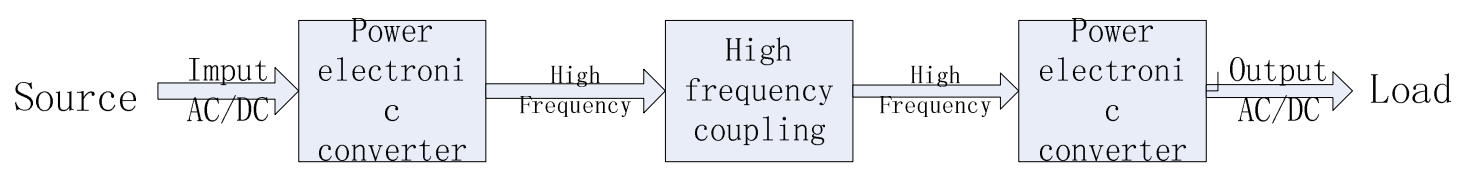

Figure 1 power electronic transformer principle diagram

there is intermediate dc link in the process of power electronic transform, PET implementation scheme can be summed up in two types: one is without dc link in the process of transformation, namely direct $\mathrm{AC} / \mathrm{AC}$ transformation. Another kind exists in the process of transformation of $\mathrm{DC}$ link, namely the $\mathrm{AC} / \mathrm{DC} / \mathrm{AC}$ transform ${ }^{[4]}$, as shown in figure 2 . This paper mainly introduces $\mathrm{AC} / \mathrm{DC}$ hybrid power electronic transformer, the $\mathrm{AC} / \mathrm{DC} / \mathrm{AC}$ power electronic transformer.

Figure 2 as a representative figure of three-phase PET circuit structure containing dc link. This is a kind of double dc structure, its working process is: the power frequency ac inputs three-phase rectifier transform for dc, then through a single phase full bridge inverter circuit it will become high frequency square wave modulation load to high-frequency transformer; Coupled to the transformer secondary side, high frequency square wave rectifier into a dc voltage, then invert to the ac output again.

This structure can realize the input power factor correction, and can suppress the harmonic of bidirectional flow. This scheme adopts integral transform structure, so the structure is simple, the number of power device is relatively few. This structure is very suitable for low voltage applications, 


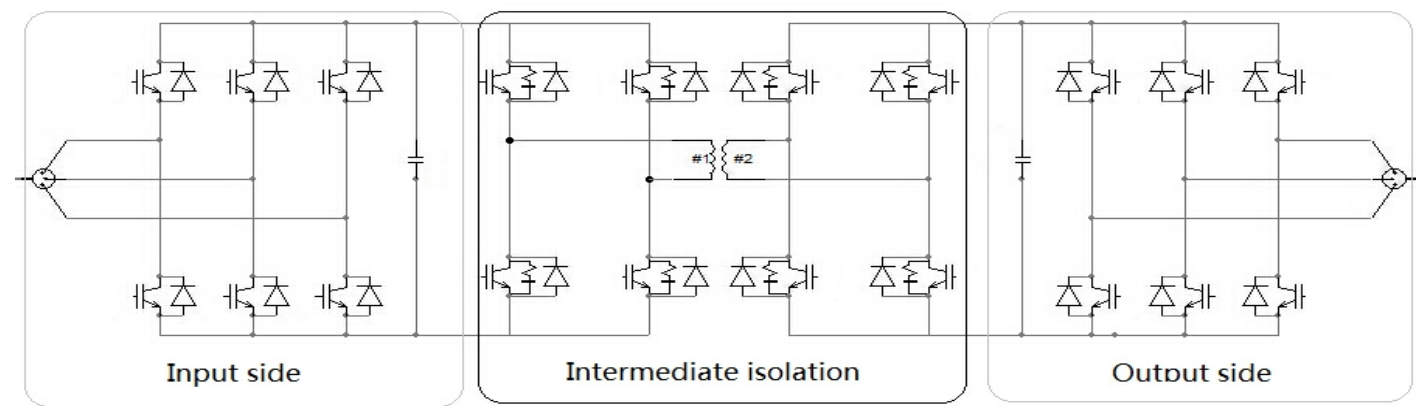

Figure 2 AC/DC/AC type PET typical structure

used in distribution network to provide high quality electrical equipment power supply. If you want to use it in high voltage class, then insist on power electronic devices with higher stress levels, and need more series, the corresponding structure will become complicated, the design will become harder.

\section{THE SIMULATION ANALYSIS}

The simulation of the paper, based on power system electromagnetic transient simulation software PSCAD. PSCAD/EMTDC, is the professional simulation software in Power System analysis, PSCAD (Power systems, Computer Aided Design) simulation is the user interface, EMTDC (Electromagnetic Transient o Direct Current) is a simulation engine as well as the core part.

Based on PSCAD software in this paper, make the three phase power electronic transformer for modeling and simulation verify, including control performance checking and the characteristics of

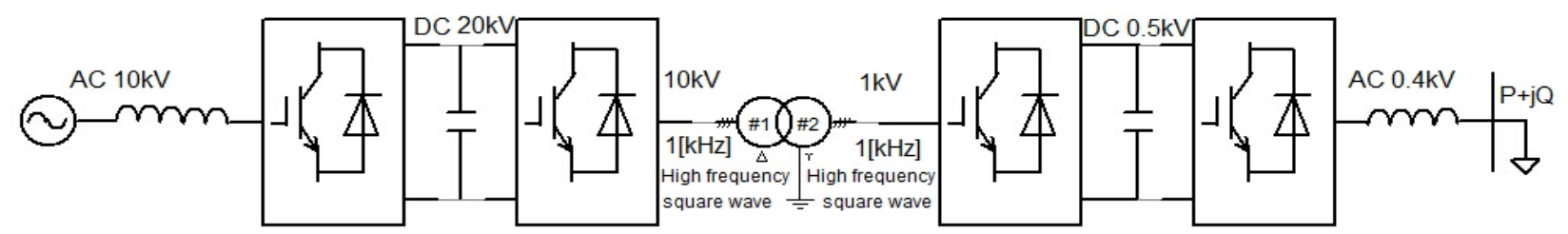

Figure 3 three-phase power electronic transformer simulation model diagram

power electronic transformer improving power quality checking, simulation is mainly aimed at the familiar distribution network in power system power quality problems: (1) the steady state operation; (2) load fluctuation; (3) harmonic simulation; (4) three phase short circuit simulation.

\section{Simulation model and main parameters}

The simulation model and some parameters as shown in figure 3:

Input stage rectifier link network side three-phase ac line voltage RMS $10 \mathrm{kV}$, frequency $50 \mathrm{~Hz}$, ac filter inductor $13 \mathrm{mH}$, dc $5600 \mathrm{uF}$, modulation ratio 0.816 , switch frequency $4950 \mathrm{~Hz}$, output dc voltage $20 \mathrm{kV}$. Intermediate level inverter circuit outputs voltage amplitude value of $20 \mathrm{kV}$, frequency of $1000 \mathrm{~Hz}$; Intermediate level of high frequency transformer capacity is $1 \mathrm{MVA}$, ratio of transformation is 20:1, the transformer frequency $1000 \mathrm{~Hz}$; Intermediate stage rectifier circuit voltage amplitude value of $1 \mathrm{kV}, 1000 \mathrm{~Hz}$ frequency, output dc voltage of $1 \mathrm{kV}$. Output stage inverter link ac filter inductance $0.5 \mathrm{mH}$, dc capacity $5600 \mathrm{uF}$, modulation ratio 0.825 , switch frequency $4950 \mathrm{~Hz}$, three-phase ac output voltage RMS $0.4 \mathrm{kV}$.

\section{Controlling method}

As a result of the traditional power diode or a thyristor rectifier circuit is composed of many defects, and its rectification produces reactive power harmonic which pollutes the power grid power quality greatly, and it becomes one of the "pollution" of power quality deterioration ${ }^{[5,6]}$. Therefore, domestic researchers have been looking for a kind of effective solution, with the progress of power electronic converter technology in recent years, power semiconductor switching device technology and computer controlling technology constantly change, a new Pulse Width Modulation (PWM) controls technology and power electronic converter technology, that is the emergence of new converter, PWM converter was produced. The coming of PWM rectifier circuit is made up for the shortcom- 
ings of uncontrolled rectifier circuit and phase controlled rectifier circuit, besides the operation of the PWM rectifier does not affect net side power quality, it is the first choice of many rectification technologies at present, so this article uses PWM rectifier power electronic transformer rectifier.

Input stage control process is: first of all, the network side of three phase current and voltage go through dq transform respectively then compare with their respective reference value, its difference will be summed up by PI regulator and the network side voltage signal with coupling signal addition, the calculated voltage signal is transformed by the dq, then the proceeds of three-phase voltage signal will be used as the PWM generator, consequently start pulse drive IGBT on-off.

Output level control process is: first, the load on the side of the three-phase voltage instantaneous value is transformed by $\mathrm{dq}$, then minus their respective reference respectively, and the difference will be set by the PI regulator then through the dq transformation, consequently we get the modulation voltage signal, this signal will act with carrier signal phase, which can trigger pulse drive IGBT on-off.

\section{The steady state simulation}

Power electronic transformer during steady state operation parameters of each link of the waveform as shown in figure 4. In the process of Simulation, active power of load is $500 \mathrm{~kW}$ reactive power is $400 \mathrm{kVar}$, power electronic transformer load side leading current is $38.62^{\circ}$. But simulation grid side of three-phase voltage and current waveform as shown in figure 4 (a) is still in phase, the power factor is close to 1, and smoothly adjustable by PWM control of power factor, effectively restrain the pollution caused by the gaps of reactive load side reactive power to grid, and stop the spread of reactive power in power grid, reduce the voltage loss greatly. Figure 4 (b) as the intermediate level high frequency transformer voltage on either side of the square wave.Figure 4 (d) (e) are a power electronic transformer, secondary side of the dc voltage one by one.

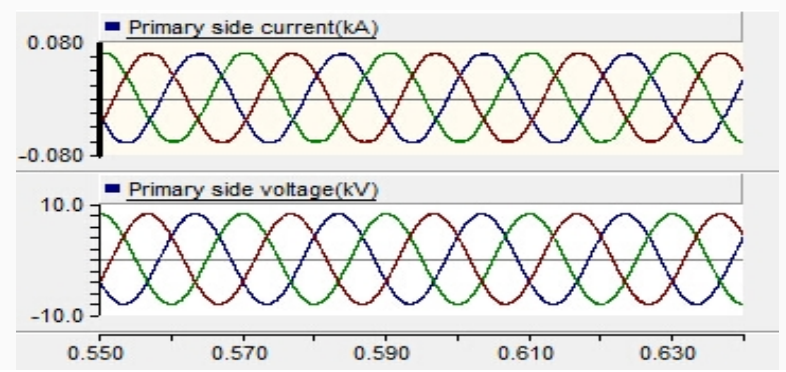

figure 4(a). Primary side parameter

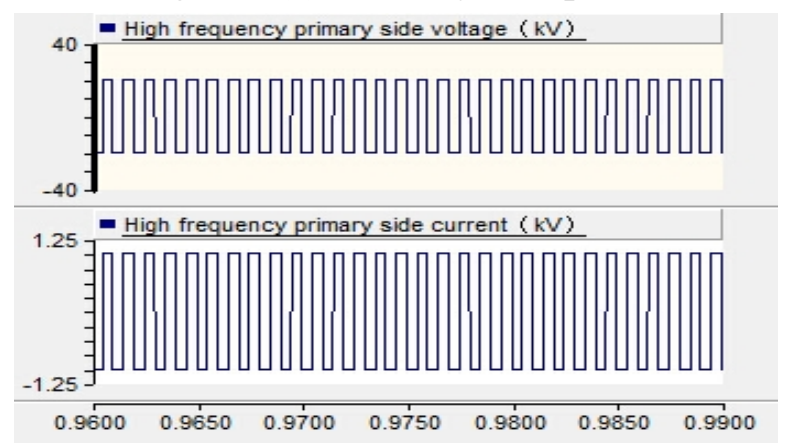

figure 4(b).Intermediate level parameter

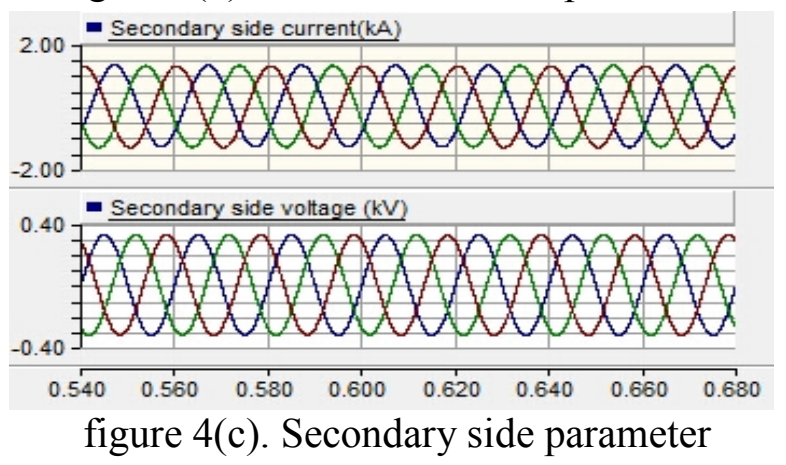




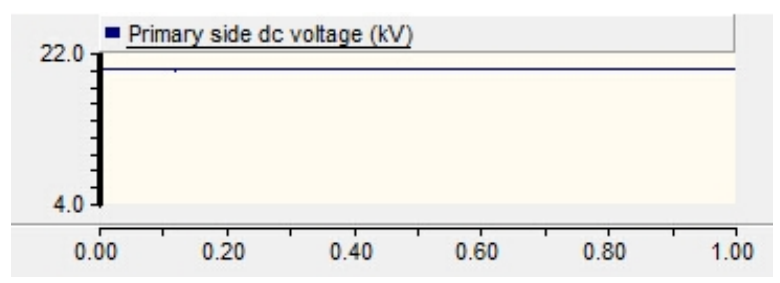

figure 4(d). Primary side dc voltage

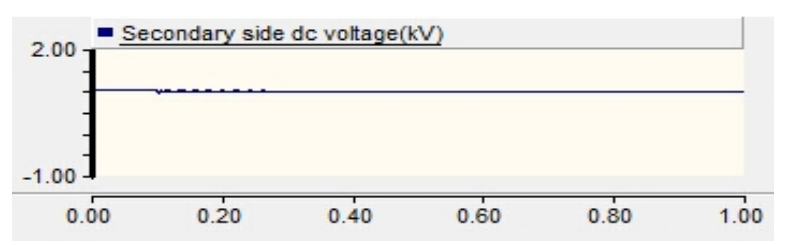

figure 4(e). Secondary side dc voltage

figure 4 . The steady state operation parameters

\section{Load fluctuations simulation}

Figure 5 (a) for the change of the low voltage side load of the PET, at the beginning of simulation the load active power is $500 \mathrm{~kW}$, reactive power is $400 \mathrm{kVar}$. Run to $0.5 \mathrm{~s}$ the three-phase active power jumps from $500 \mathrm{kw}$ to $600 \mathrm{~kW}$, reactive power increased from $400 \mathrm{kVar}$ to $450 \mathrm{kVar}$, run to $0.6 \mathrm{~s}$ active power comes back to $500 \mathrm{Kw}$ again, reactive power becomes $400 \mathrm{kvar}$. Figure 5 (c) for the changing of PET secondary side current voltage. Figure 5 (b) as a primary side current voltage waveform graph, it can be seen that the load fluctuation doesn't have any effect on primary side parameters.

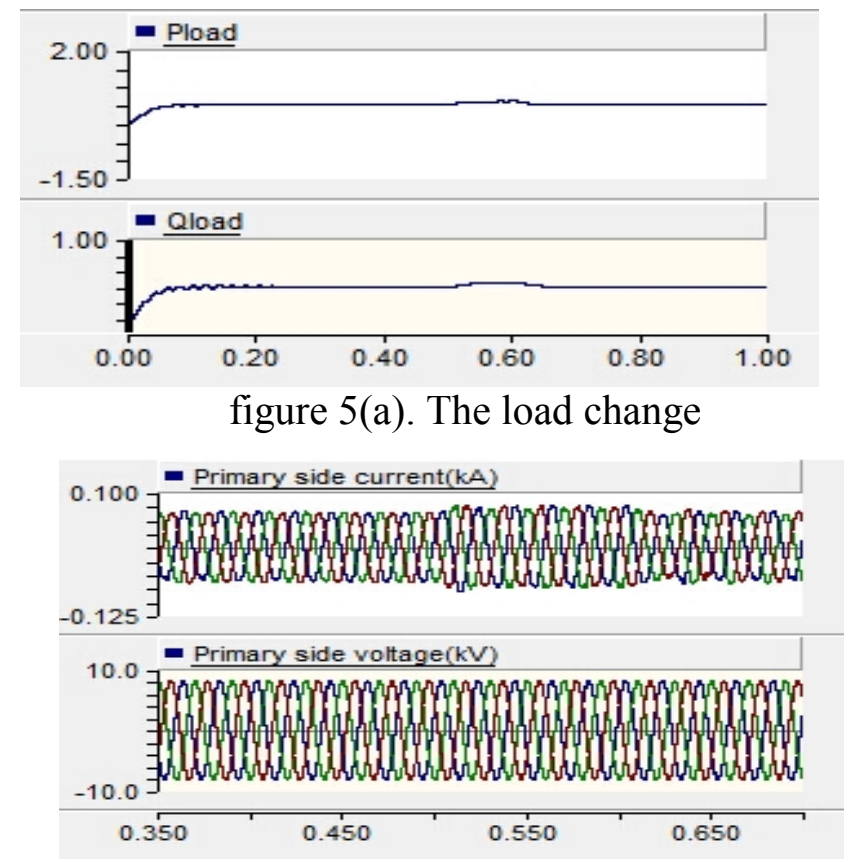

figure 5(b). Primary side parameter 


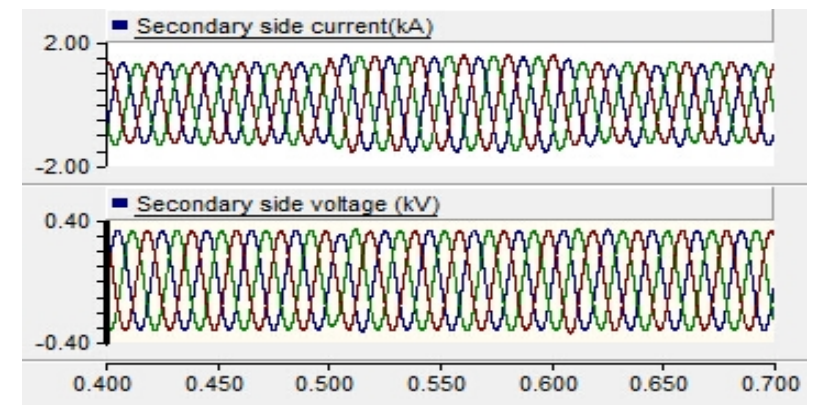

figure 5(c). Secondary side parameter

\section{the harmonic simulation}

figure 5 . The influence of load fluctuation on voltage

Figure 6 for the situation when load side voltage containing harmonic(add a harmonic source to the load side). Can be seen from the diagram that containing harmonic load side voltage of the side of the net voltage is still the standard sine wave voltage.

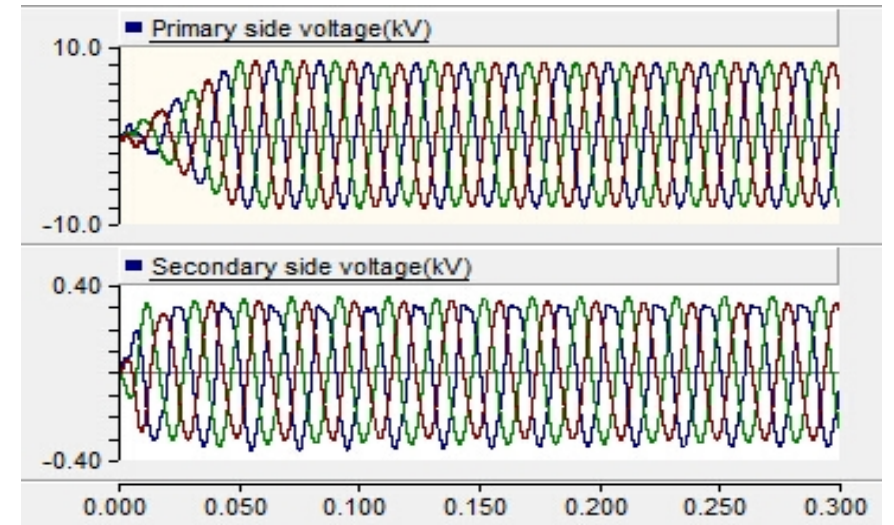

figure 6. Load side voltage harmonic disturbance

\section{Three phase short circuit simulation}

Figure 7 for the parameters when the system is running to $0.5 \mathrm{~s}$ load side happen three-phase symmetrical grounding short-circuit (short-circuit continuous $0.05 \mathrm{~s}$ ). By the figure can be seen that when the load side three-phase grounding short-circuits, the three-phase voltage reduces to 0 , after fault resection about $0.1 \mathrm{~s}$ of adjusting the voltage goes back to normal, but in the whole process grid side voltage has not changed. 


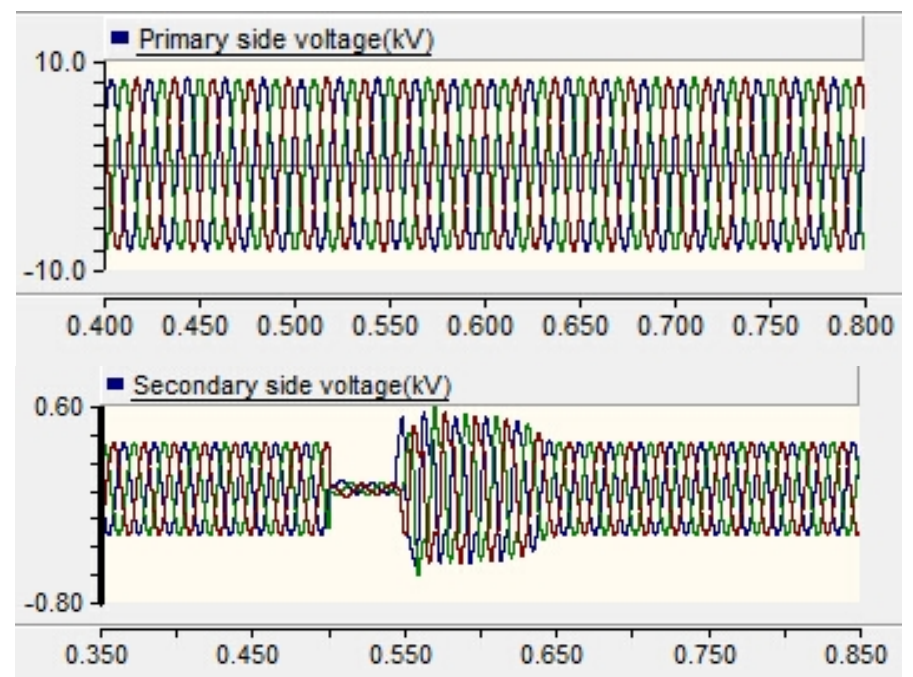

figure 7. Load side three-phase symmetrical short-circuit

\section{CONCLUSION}

The result of simulation shows that power electronic transformer not only does have the basic function of traditional transformer, due to its link of ac and dc at the same time, so a PET can also adjust the power quality, for example, power electronic transformer outputting stage is controlled by a set of ac voltage, even though the secondary side load fluctuating secondary can maintain a constant outputting voltage; Power electronic transformer can inhibit such as harmonic, symmetrical short circuit fault, this is the most significant features of PET and the function which the traditional transformer does not have.

Although the power electronic transformer has many advantages that traditional transformer does not have, but it is, after all, a new technology, currently the theory is not complete enough, it needs further research. So in the future the research of power electronic transformer needs a long period of time.

\section{REFERENCE}

[1] Transformer manufacturing series editor committee(ed.),1998. Transformer winding manufacturing process. beijing: Mechanical industry press.

[2] Jianfeng,Zhao.2003. The output voltage constant simulation of power electronic transformer. Automation of electric power systems0327(18):30-33.

[3] Chengxiong, Mao \& Dan, Wang \& Shu, Fan \& Jiming, Lu (eds).2010. Electronic power transformer. beijing: China electric power press.

[4] Manjrekar,M.D. \& Kieferndorf,R. \& Venkataramanan,G.2000. Power Electronic Transformers for Utility Application. Conference Record of the 2000 IEEE Industry Application Conference: 2496-2502.

[5] Xiaopin,Xu.2004. Three-phase PWM rectifier is studied. zhejiang: Zhejiang university.

[6] Feng,Jie.2006. Three-phase PWM rectifier and its control. zhejiang: Zhejiang university. 